\title{
In-service Learning in a Pre-service Teacher Training: The Dilemma of an Adult Learner in Botswana
}

\author{
Mhozya, C. M. \\ University of Botswana \\ E-mail: cynthiamhozya@yahoo.com \\ Pansiri, O. N. \\ University of Botswana \\ E-mail: pansirio@mopipi.ub.bw \\ Bulawa, P. \\ University of Botswana \\ E-mail: bulawap@mopipi.ub.bw \\ Moletsane, N. T. \\ University of Botswana \\ E-mail: moletsan@mopipi.ub.bw
}

Received: August 15, 2012 Accepted: September 19, 2012 Published: November 1, 2012

doi:10.5296/jse.v2i4.2246

URL: http://dx.doi.org/10.5296/jse.v2i4.2246

\begin{abstract}
Many universities across the world offer full time programmes not only to younger students directly from formal basic education programmes such as secondary schooling but also to in-service or adult learners. In-service learners are serving or non-serving but experienced and mature students who are afforded an opportunity to enrol in full-time or part-time programmes. As such, higher education institutions are inevitably challenged to service both younger and adult learners under one roof. Exploring challenges faced by adult learners in higher education institutions full-time programmes can therefore no longer be ignored in many developing countries. Some institutions may have taken a more transformative move to create an adult learners' responsive academic environment, while others may have not. Based
\end{abstract}


on the continuing professional development approach, this case study investigated the full-time in-service teachers' experiences as adult learners in Botswana higher education institutions. It further sought the views of lecturers of adult learners and education officers regarding their experience with the learners. The key findings include institutions' neglect of adult learners' social needs, subjecting them to the dilemma of having to either drop out or continue under stressful learning environment. In the final analysis, support systems to mitigate challenges encountered by adult learners in the academic environment are recommended.

Keywords: Adult learners, Continuing professional development, Socio-emotional challenges, Academic challenges, Economic challenges 


\section{Background}

Like many developing countries, Botswana is still struggling to produce adequately trained teachers. It has teachers with low qualifications, some semi-trained and others untrained. In the early 2000s it became clear that the country's trained teachers were mostly lowly trained. According to Pansiri (2007), by 2009, the Botswana teaching service establishment at primary school level was $71 \%$ certificate, $26 \%$ diploma and $4 \%$ degree holders. The secondary schools establishment was 73\% diploma, $18 \%$ degree and $0.8 \%$ postgraduate degree holders. In this case, continuing professional development has become a policy not just to improve teachers' professional practice, but to also upgrade their qualification (Republic of Botswana, 1994) with the desire and hope to improve the quality of the education system. Consequently serving teachers are sent yearly to colleges' or universities' full-time programmes to upgrade their professional qualifications, where they participate as in-service adult learners.

In this teacher up-grading effort, there has been a taken-for-granted approach that assumed smoothness in the program delivery and teacher - learner professional relationship. For example, issues of enrolment decline in teacher in-service programmes (Pansiri, Mhozya, Moletsane \& Bulawa, 2012) have not been interrogated. It is against this observation that the following research questions have been generated.

a) Are adult-learners benefiting from the programme delivery as offered by the University of Botswana (UB) and Colleges of Education?

b) What are the perceptions of lecturers in UB and Colleges regarding adult learners?

c) What are the perceptions of adult learners with regard to professional relationship with lecturers?

d) What are adult learners' preferences/choices for type of higher academic programmes?

\section{Literature Review}

While there is limited literature about the experiences of full-time in-service teachers in academic programmes in Botswana, research elsewhere has established that "adult learners have unique characteristics that set them apart from younger students" (Ausburn, 2004, p. 328). It is argued that adult instructors should take careful consideration of the characteristics of adult learners (Huang, 2002). For instance, compared to young learners, adults require "specific interventions, models and services” (Kasworm, 2010, p. 145). Kasworm (2010) also argued that in-service learners "considered themselves deficient because they were too old and perhaps no longer capable of the intellectual demands of the classroom” (p. 145). They were fearful of humiliation in a mixed-age academic environment. If they found themselves in such a predicament, they preferred to make conscious choices on what to or not to learn (Illeris, 2003). In other words adult learners are prepared to learn provided their life situations create a need to learn (Huang, 2002). 
The literature on adult learners has also revealed "difficult social and economic factors" that interfere with adults' persistence in learning (Crowther, Maclachlan \& Tett, 2010, p. 652). Furthermore, Crowther, Maclachlan and Tett (2010) maitained that pedagogical practices impact on the progression of adult learners, pointing out that positive learner-tutor relationship was paramount for the adult learner. They also found that adult learners were likely to persist with their learning where there was support from staff so that they (learners) established clear goals which would enable them to identify increased self-efficacy. As noted by Ausburn's (2004) study, adult learners "placed high value on effective two-way communication with their...instructor and felt they benefitted from frequent announcements and reminders from their instructor” (p. 334).

Emotional and pedagogical experiences and identity were found to have a link with the learners' age. Laot (2010, p. 669) argued that one of the abnormal phenomena found by researchers is that "adults [were] being taught by teachers as if they were children or young people". As stated earlier, Kasworm (2010) indicated that adults dismissed themselves in terms of age and capabilities to cope with the pedagogical pressures. Coker's (2003) study amongst adult women learners revealed that some women felt anxious about their ability to do their school work after having been away from school environment for a number of years, in comparison to "recently conditioned learners who had not taken off time away from school” (p. 668). Another observation made by Coker (2003) is that women adult learners indicated that they felt marginalized as adult learners, and their "feelings manifested themselves in terms of academic ability, relationships with faculty, and interactions with others” (p. 668).

Factors of identity and social networks (Crowther, Maclachlan, \& Tett, 2010) also feature in literature on adult learning. These have been found to instrumentally encourage resilience towards academic engagement. The choices they make were also as a result of identity and social networks factors, and what Crowther, Maclachlan, and Tett call "community of practice” (p. 660). The argument is that the community of practice provides adult learners with a broader range of opportunities to participate in learning programs. For example, Huang (2002) emphasized that adult learners could actively participate in "the course design including course objectives, prerequisites, the grading scheme, and teaching materials” (p. 34).

Brownlee, Purdie and Boulto-Lewis (2001), argued that in teaching, in-service learners were those who have acquired "...school teaching experience, training experience in the workplace, tutoring experience, parenting experience, helpers at camps and church functions, classroom volunteers, working after school care, and working as a teacher aide” (p. 6). This effectively means that in-service adult learners bring a host of varied field experiences into the pre-service college or university learning environment. They have a professional qualification and accumulated practical experience. They enroll with a college or university to upgrade their qualification in order to increase their competitive advantage in their professional career progression. They take a calculated risk and have the courage to participate in a complex journey of being students as well as being committed community service providers concurrently. A study on adult women students conducted by Johnson, Schwartz and Bower 
(2010) shows that many women who enroll to further education are not able to complete their programmes since "they cannot cope with double or triple burdens of family, job, and school" (p. 289). Coker (2003) also made reference to the double roles played by women as adult learners and their social responsibility as community leaders. Against this background, it becomes increasingly critical for an institution to identify the needs and wishes of adults as learners (Ausburn, 2004). For instance, an institution has to recognize, among other things, the need "for a greater emphasis on emotional-focused coping strategies as people age..." (Lockenhoff \& Carstensen, 2004, p. 1409).

\section{Conceptual Overview}

This study is based on the concept of continuing professional development (CPD). CPD is the systematic maintenance, improvement and broadening of knowledge, skills and competence throughout a professional's working life (Kostadinovic, 2011). It is an on and off site process of ensuring lifelong learning for professionals to improve performance. In the UK and other western economies, CPD has become a policy that is institutionalized for its lifelong learning imperatives, personal development, individual development, updating professionals in the rapid pace of technological advancement, verification and upholding of professional standards and for ensuring competent and adaptable workforce (Fraser, Kennedy, Reid \& Mckinney, 2007). CPD practice ensures that professionals engage in learning from the day they enter their professional practice to the day they retire, given that initial professional training often "cannot contain all of the propositional knowledge that is needed and certainly not that is procedural” (Knight, 2001, p. 230). CPD is therefore a tool that ensures increased retention of professionals and enhanced service delivery (Armour \& Yelling, 2004).

CPD is an emerging global acclaimed virtue for organizational effectiveness and efficiency. This has actually become a legitimate demand by both employees and organizations that hope to effect change in employee's competencies and organizational practice. This legitimacy has intensified with the pressure of globalization and related neo-liberal economic policies which have been encapsulated in the demand for competition, quality and increased productivity (Pansiri, 2011). Most universities in the market-driven economy are generally youth-oriented academic institutions that also have segments of adult learners. While learners at this level are those reasonably mature people, who would have made their own independent choices for the type of higher academic programmes that are in line with their career dreams, the distinction between an in-service or adult learner and a young learner and their identity in a university seems also obvious. Young learners may be largely those who join a university/college directly from a secondary school experience in their twenties, and in-service or adult learners are those chronologically older persons who have a professional qualification and an accumulated practical experience and are only entering a university/college to upgrade the qualification. Their educational dream is, more often than not, influenced by the desire to increase their opportunity, possibilities and hope, in the not so bright a competitive career and future. The education sector, which is viewed in many ways as the engine for economic development and social change, has also embraced the CPD for teachers. In the developed countries, for example, CPD for teachers came in many forms such as short courses, school-based in-service education and training, or long term lifelong learning for career 
development (Brownlee, Purdie \& Boulto-Lewis, 2001).

Botswana has also gotten into the CPD framework by adopting an education policy which calls for both on site and off site in-service for teachers (Republic of Botswana, 1994). For example, the policy pertaining to on-site CPD recommended that, "the heads as the instructional leaders, together with the deputy and senior teachers, should take major responsibility for in-service training of teachers within their schools, through regular observations of teachers and organizational workshops, to foster communication between teachers on professional matters and to address weaknesses” (Republic of Botswana, 1994, p. 47). For the off-site, the policy advised the government to replace the certificate qualifications in the teaching profession with a minimum of diploma qualification. As a consequent, since 2000 the country is running college-based in-service CPD for upgrading teachers' qualification from certificate to diploma and higher degree qualification. The in-service adult learners who join either college or university full-time CPD programmes are mainly in their late 30s to mid 40s. They would be oblivious to the truism that time is limited to their side. They would therefore need to as quickly as possible acquire more knowledge, resources and better their socioeconomic status to prepare for their immediate future. As such they develop a "sense of urgency to academically succeed...” (Kasworm, 2010, p. 143).

Revered for being a CPD in-service department, the Department of Primary Education of UB has since its inception in 1980, enjoyed admitting mostly government fully sponsored serving teachers to its programme. One of the Botswana's institutions offering CPD, the Francistown College of Education also shifted from being a mixed intake of both pre and in-service to a wholly in-service college in 2008. This shift was meant to speed up the phasing out of certificate holders at primary school teaching level which is a response to the 1994 education policy imperatives that demand an improved image of the teaching profession. The policy requires a minimum of qualification of a diploma in a public primary school classroom. This policy (Republic of Botswana, 1994, p. 45-47) firstly, required the upgrading of all primary school teachers training institutions from certificate qualification to diploma. Secondly, it introduced a new type of teacher programme that has subject specialization and specialized instructional innovations at primary education level. The policy proposition pressurized teachers to engage with adult learning or else they would face what Illeris (2003, p. 14) call "social and economic marginalization". The Botswana case is more or less similar to the Denmark situation where "the majority of [adult learners] ... are forced or persuaded to [enroll] either ... by employers or authorities...” (Illeris, 2003, p. 14). To many of the teachers in Botswana, upgrading to diploma qualification or beyond potentially increases the clients' opportunities for the nature of an uncertain competitive career and pursuits of personal image in the teaching profession.

\section{Research Design and Methods}

The principal aim of this project was to establish whether the teacher-up-grading programmes offered at Francistown Colleges and University of Botswana fit the purpose and expectations of both learners and lecturers. The study adopted a mixed-methods strategy. Social science research has been guided by either quantitative or qualitative paradigms. The quantitative 
design is the oldest positivistic-empiricist epistemological assumption in which knowledge and truth are discovered through reliable, valid and objective rigorous and systematic rules (Coolican, 2004), while the qualitative is the hermeneutic-interpretive epistemological assumption that is informed by the rule that knowledge, truth and reality are socially constructed through the use and interpretation of language, consciousness and shared meaning (Schwandt, 2000). These two traditions have remained parallel social science research methodological stances for quite sometime. The mixed-method approach is the newest paradigm which is a more pluralistic application of methodological approach that rejects rigidity or fixation to either of the paradigms. This study used a combination because this research project is not just for mere scientific research but to practically and purposefully inform policies and practices on the support for in-service learners. This approach is further necessitated by Onwuegbuzie's and Leech's (2005) argument that what matters most are the research questions rather than positivistic-empiricist nature of the quantitative or the hermeneutic-interpretive dimension of the qualitative techniques of the research strategy. This choice of methodology was influenced by the growing contemporary argument for the combination of both qualitative and quantitative designs in a single study (Tashakkori \& Teddlie, 1998; Onwuegbuzie \& Leech, 2005; Brannen, 2005; Lockyer, 2006). Through this approach, the research activities gain the flexibility for the "multiple methods and data sources...” (Stark \& Torrance, 2005, p. 33).

In approach, the sequential exploratory model (Creswell, Clark, Gutmann \& Hanson, 2003; Onwuegbuzie \& Leech, 2005) was used. The model enabled researchers to identify instances of relationships in perceptions from the two data sources. The model develops from qualitative to quantitative stances. The strategy allowed complementary manner of data collection and analysis methods and help researchers to establish a comprehensive picture about the problems in the field under study (Tashakkori \& Teddlie, 1998). The two sets of data are integrated to complement each other as well as developing a comprehensive understanding on the issues affecting in-service learners enrolled in in-service education programmes. It has been argued that in sequential exploratory design, the quantitative data "assist in the interpretation of the qualitative findings" (Onwuegbuzie \& Leech, 2005, p. 22). Onwuegbuzie and Leech also argue that the sequential exploratory model is a data collection and analysis methodological technique that gives priority to qualitative approach. The adoption of this model was therefore considered appropriate for this study.

\subsection{Population of the Study}

The population of the study was the current and former students of the DPE programmes of study, namely B.Ed. (Primary), B.Ed (Management) and M.Ed, stakeholders (lecturers of a Francistown College of Education and education officers). These categories of the population were adult learners, in-service providers and teacher managers. They were able to share with the researchers their perceptions as students, in-service teacher educators or teacher managers.

\subsection{Sample and Sampling procedures}

The study was carried out in three phases along the qualitative, quantitative and seminal 
designs. Phase one was a qualitative approach and involved ten participants in year 2, ten in year 3, ten in year 4 (five participants per each of the two bachelors degree programmes) and five participants in the $\mathrm{M}$ Ed programme. These participants were selected through opportunistic and convenience method, (Patton, 2002; Ritchie, Lewis \& Elam, 2004). These methods allowed researchers to involve any DPE learner who was accessible, thus 'taking advantage of the unforeseen opportunities as they arise during the course of the [study]' (Ritchie, Lewis \& Elam, 2004, p. 81).

Phase two was a quantitative approach which involved of respondents (both current and former in-service learners). As Creswell (2007) pointed out, a systematic random sample is where every $n$th subject in the population is chosen until a desired sample is reached. Using this method, out of the 300 questionnaires randomly distributed, 164 returned ( $n=164$ respondents). This sample is considered appropriate for this study.

Phase three was a seminar with ten college lecturers who teach in-service teachers in a diploma upgrading programme and seven education officers who send teachers for upgrading. This seminar afforded the opportunity to share ideas about the experiences of the parties involved.

\subsection{Data Collection}

Data collection strategies included interviews, questionnaires and seminal discussion. Data analysis was guided by the same process. The study was spread over a period of university academic year, which is twelve months. To start with, a qualitative data collection and analysis approach was used. Documentary review and interview (Patton, 1987; Patton, 2002) were used. These methods enabled the researchers to collect data on challenges faced by the learners through official documents review. Bogdan and Biklen (1992, p. 147-148) argue that official statistics "can suggest trends in a setting...provide descriptive information... about the population served by a particular educational program.” The documentary review helped to generate variables that were investigated through interviews. The interviews were used further to assemble and prioritise sets of possible feelings and perceptions of the target population groups. During this hermeneutic-interpretive process of the two data collection stages, the researchers made preliminary analysis to identify emerging themes, issues and factors which were then confirmed further through the likert-type scales questionnaires, the positivistic-empiricist process.

\subsection{Data Analysis}

The study used a sequential exploratory approach of the mixed methods model in which priority was given to qualitative approach. Data from the descriptive text (qualitative) were analysed through the codes, coding schemes and categories to come with variables that pointed to perceptions of in-service learners. The numerical data (quantitative) were analysed through the SPSS to come up with analysis of variance (ANOVA) of predictable assumptions. The results were discussed in a stakeholder seminar where other ideas about adult learner experiences were generated. 


\section{Findings and Discussion}

The study was in three phases. This discussion is therefore guided by the three stages. Phase one was a qualitative approach that allowed direct interaction between researchers and in-service learners over their livelihood as adult learners. Three major themes emerged in the interactions namely socio-emotional, academic and economic challenges that learners face in their time as in-service learners (Pansiri, Mhozya, Moletsane \& Bulawa, 2012).

In the teacher in-service programmes, learners remain conscious and particular of who they are. Various pointers to this phenomenon emerged in the interviews and focused group discussions. In terms of their age participants raised observation that they were referred to as the group of mature students. One of the participants echoed, 'They refer to us as 'Bo-mature' meaning mature entry student and often wonder why we are at the university at our age'. The way they were looked at by the majority of the students, mainly of younger age, bothered the in-service adult learners. For instance, calling these students 'Bo-mature' was not only reference to age difference, but a label deliberately intended to ridicule them for coming to school when they were old, hence the comment by one of the adult learners, "We wonder why we are at the university at our age'. This is reflective of Illeris's (2003) observation about adult learners being fearful of humiliation in a mixed-age academic environment.

There was consensus among college lecturers attending stakeholder seminar regarding some academic challenges faced by college adult learners. They indicated that these learners' comprehension of academic issues was slow, something they attributed to old age. They cited mainly students who were doing mathematics and science as being the most affected. In their view, occasionally some of the affected learners were compelled to discontinue their study as they could no longer cope with their academic work.

Relating their early life experience at college or university, the in-service adult learners reported that they nearly gave up. Statements such as, 'I felt belittled and undermined and as a result I nearly dropped out and went back to my work' shows that as much as they were students, they were frustrated by the seemingly hostile environment which did not recognize their status as adult learners. For example, a school head would expect treatment that recognizes his/her status. So the mismatch between their status as students and as teachers or school managers caused them emotional stress.

The questions of social responsibility as members of the community also surfaced. For example, some had tough time trying to balance social responsibility and academic attention hence comments such as, 'Even at home people feel that she is now educated and is not coming home for funerals ...may even be deciding to divorce because she is educated than her husband'. College lecturers and stakeholders also endorsed the observation that adult learners' social responsibilities remain bleak. This indicates the magnitude of the problematic nature of committing time to academic work over domestic demands. Making decisions about choice of courses in the adult learners' programme of study was described as problematic. Expressions such as, 'There is no one to guide us on elective and optional courses. When you come here you are given forms. You rely on those forms to pick up the courses, only to realize that when time goes on that you have taken a wrong course' were echoed consistently. These 
concerns bear testimony to Ausburn's (2004) study about the value that adult learners place on effective two-way communication between the students and their instructor for them to benefit from their studies.

Carrying a burden that demanded their economic attention affected adult learners' studentship. The learners made comments such as, 'As a single parent, a mother of 4, having grand children and other people to take care of, coming here, ... I nearly dropped... because I had a loan and then went into half salary' which reflect the nature of challenges they go through while they pursue their studies. Similarly, stakeholder participants revealed incidents of learners who joined college when they already faced such social challenges as breakdown of marriages, ill health among family members, abuse by spouses, which they described as prevalent mainly among women, and personal debts which sometimes resulted in some of them being arraigned to the courts of law. Against this backdrop, it is important that adult instructors take into account the unique characteristics of adult learners in comparison to young learners (Huang, 2002).

Drawing from these socio-emotional (Lockenhoff \& Carstensen, 2004), academic and economic experiences of the participants, some issues for further verification were identified. A three section likert-scale questionnaire was developed. The sections explored predictions of the socio-emotional, academic and economic experiences of in-service learners. Critical variables used in the questionnaire were gender, age range at first enrolment at UB, position of responsibility, qualification, experience/length of service, and status or full/part-time type. One hundred and sixty-four $(n=164)$ respondents filled the questionnaire. In terms of gender, $29 \%$ were males and $71 \%$ were female. The age range was $3 \%$ of the $20-30$ years, $18 \%$ of the 31 - 40 years, and $79 \%$ of the 41 years and above. The distribution of respondents according to position held was $21 \%$ were teachers, $17 \%$ were school heads, $10 \%$ were deputy school heads, $24 \%$ were heads of departments, $23 \%$ were senior teachers, $4 \%$ were education officers. Qualification or respondents were as follows: 72\% were B Ed (Primary), 9\% were B Ed (Educational management), 4\% were BA, 4\% were M Ed holders. As for status, 95\% were full-time learners and $4 \%$ were part-time learners. The age of first enrolment at UB 20 30 years were 22\%, 31 - 40 years were 53\%, 41 years and above were $24 \%$.

In analysis, the one-way ANOVA on the significance value of $\mathrm{p}=.05$ was used. This helped to estimate the amount of variance to account for respondents differences in perceptions of the in-service programmes.

The study investigated as to whether adult learners were allowed to participate in learning at their own pace. The results indicated the differences in perceptions in terms of gender with ANOVA of .014 degree of significance. This suggests that male and female learners experience learning autonomy differently. In the context of Botswana research has shown that $47 \%$ of households are female headed (Akinsola \& Popovich, 2002)., These results are therefore not surprising because even though these women have enrolled for full-time studies, they still have family commitments which they often have to balance with university course commitments. This finding is in line with women elsewhere as revealed by Johnson, Schwartz, and Bower (2010) which shows that many women who enrolled to further their 
education were not able to complete their programmes since they could not cope with double or triple burdens of family, job, and school.

Learner participation in social activities was examined. The results reflect that gender accounts for an ANOVA of .000 degree of significance. This shows a huge difference between male and female learners on how they experienced participation in UB social activities. The findings also revealed the differences in male and female personal engagement in UB social activities which accounts for an ANOVA of .002 degree of significance. Furthermore the results also show a huge difference for an ANOVA of .000 degree of significance in male and female participation in recreation and extra mural activities. On average we found that female adult learners enrolled at an older age than their male counterparts and found that university social activities did not cater for their interests and this was further compounded by the fact that often they had numerous other social commitments in the community such as church groups, 'motshelo' (informal group savings system)' and others which occupied an available time. It also became evident that female learners also preferred to be spectators instead of actively participating in recreation and extra-mural activities.

The differences between male and females also emerged when they were asked whether lecturers recognized their social responsibility which account for an ANOVA of .031 degree of significance. Female learners expressed concern that lecturers did not appreciate many of their social commitments, neither did they recognise the many hats that they had such as head of family, extended family elders, and church elders which often required them to play significant roles in weddings and funerals. The social responsibility of adult women learners as leaders of their community which increased, among other things, their sense of identity is also highlighted by Coker (2003). The seminar participants also confirmed that the learners are from time to time compelled to leave school to attend such social obligations as funerals and weddings of family members. Lecturers were also asked if they enjoyed teaching adults. With only one exception, all were positive. Reasons given shared a commonality across the stakeholders. Words such as highly motivated, enthusiastic and committed were used to express their positive feelings.

Under economic challenges, the findings indicated that the male and female differed when they were responding to whether UB provided employment opportunities for adult learners on an ANOVA of .004 degree of significance. The difference for an ANOVA of .012 of degree of significance also emerged when male and female were asked whether subsidized transport was available for them. Regarding subsidized health services provision the findings showed the differences of male and female response with an ANOVA of .011 degree of significance. This difference could be accounted for by the diverse representation of various Ministry of Education departments which provide different benefits for their employees. Furthermore, increased family, financial and social responsibilities for female learners put a heavier strain on their finances and such would require more extensive tailor-made subsidies. Under Environmental challenges the differences emerged when the researchers wanted to know whether male and female got support from family and friends. The differences accounted for an ANOVA of .035 degree of significance. Despite the level of social 
development in Botswana society, women in leadership positions or career driven females still encounter negative perceptions on the role of women in society. Many of their families still feel that a woman's role is that of attending to household responsibilities, and so many of the adult female learners encountered resistance from their families and are often accused of neglecting their families and their social commitments.

The differences also emerged in age range and academic program when learners were asked whether UB had induction programme for students on arrival. The issue about an induction programme is critical because as Crowther, Maclachlan and Tett (2010), point out, positive learner-tutor relationship is paramount for the adult learner. The findings indicated a difference on an ANOVA of .018 degree of significance. This difference could be accounted for by the fact that there are many flaws and delays in the processes relating to adult learners, such that many of them are often given short notice of their admission and therefore many often have to forego orientation in order to be able to finalise their household and personal matters. They often arrive at the university after the UB orientation week. The issue of students' late arrival was also raised at stakeholder consultative seminar held in Francistown. Participants indicated that some students miss vital information about their learning environment because they arrive late at college when orientation activities have already been conducted. On a positive note, participants also reported that they have a belief that adult learners can make a serious commitment to college studies. They suggested that they often reflected an ideal college image, because they had to make a conscious choice in their lives to pursue college while maintaining other significant adult life roles. Adult learners' academic destructions are serious - making money, taking care of families, keeping relationships, supporting marriages are just too overwhelming. According to Kasworm (2005), these concerns represented the paradoxical nature of adult students' judgement of themselves. Another reason may be that adult education programmes may in fact have inadequate induction programmes perhaps due to the fact that it is assumed that everyone enrolling has a tertiary institution foundation and thus induction is done on a superficial level rather than the comprehensive ones catering for recent high school graduates. An ANOVA of .015 degree of significance also reflected the in students' age range and participation in UB social activities/engagements. This difference can be explained by the fact that the older learners tended to feel that the social activities did not cater for their interests and very often they cited that behaviour at some of these activities was unsavoury to most of them.

Furthermore, an ANOVA of .039 degree of significance emerged between age of first enrolment at UB and in whether ICT courses provided students with basic computer skills. ICT for in-service adults is a new innovation which was not there during their teacher training yesteryears and therefore they need a robust course that engages them in one to two years of practical experience. Most learners in different faculties in UB are offered the ICT course for a semester. This study discovers that most pre-service learners in UB have done basic computer courses prior to enrolment as compared to the adult learners who have had limited exposure to computers. So, for a poor-computer literate adult learner to be in the same class with these young computer-literate learners it's a nightmare. Learners reported that the course tutors tend to cover material too quickly and rashly, and thus leaving bo-mature (adult 
learners) behind and frustrated. Some participants also indicated that adult learners found it more difficult to learn some ICT skills, and as such more time was spent trying to help them.

The differences emerged in age at first enrolment at UB and lecturers appreciation of students' pressure in balancing academic and social responsibility where it reflects an ANOVA of .015 degree of significance. The older adult learners tended to have more responsibilities and commitments than their younger counterparts. Learners felt, unfortunately, that their lecturers were not sympathetic to their plight or lacked appreciation of the extent of their social commitments.

The differences were also found in positions held before joining the university. An ANOVA of .023 degree of significance was recorded. It therefore means that adult learners who held high ranking positions tended to feel that theory alone did not contribute significantly to their learning. They indicated that practically-based learning was more beneficial as it provided them with real life scenarios and interactions which appeared more relevant to their day to day work problems. This could partly be attributed to the point raised by some participants that as lecturers of adults, they lack skills required to handle adult learners. This situation does not only frustrate the learners but also the lecturers themselves. Furthermore the differences emerged in positions held and whether students adequately prepared for study leave. An ANOVA of .017 degree of significance points to this difference. As revealed by the stakeholder seminar participants, some adult learners are nominated for study leave on a short notice by the department of Teaching Service Management (TSM) and therefore those holding high positions were required to hand over their duties and responsibilities to the senior management team. This handing over took place over a period of time. An ANOVA of .002 degree of significant was found also in positions held against students support from friends and family while in UB studying. The difference also emerged in positions held against availability of computers for student to do work on an ANOVA of .047 degree of significance. Some adult learners in leadership positions come from a background where many of them had their own offices and access to computers but when they come to the university they face a situation where they have to share study spaces and compete for computers with other younger learners. Also students' status and whether they were given the opportunity to participate in UB based part-time jobs showed a huge difference with an ANOVA of .000 degree of significance. Many factors could contribute to this discrepancy. Firstly, there is a belief that the adult learners who come from high positions were thought to have enough income as their salaries were higher than those of the other adult learners. Secondly, it could be that the part-time jobs may not be within their area of expertise or seen to be basic to them and thus not offered.

\section{Conclusion and Recommendations}

What is significant about the findings in this study is that while Botswana education system has embraced CPD for its teachers with more and more of its serving teachers entering the university for either undergraduate or postgraduate programmes, they face challenges that adversely affect their studies. Much as they may be determined to acquire their degrees, the roles as mothers, fathers, sisters, brothers and community leaders make it very difficult for 
them to balance their academic life and that of their social family life. For instance, unlike younger pre-service learners mainly fresh from high school adult learners find themselves having to deal with difficult economic and social demands at a period when they should be focusing on their studies.

The learning experiences of adult learners in higher education are shaped by a number of factors such as the culture of the college, the teaching styles of lectures and the rigours nature of academic study. For some this was a painful process as they had to abandon their idealistic views of what they thought university study would be like. Despite this, the impact of learning was significant as all participants felt that the self had changed and developed. As concluded by Pascall's and Cox's (1993) studies, adult learners ended up feeling empowered and identities changed by significant learning processes.

What further comes through in this study is the feeling amongst adult learners that the university environment does not support their course. For instance, the views of the younger learners about adult learners are that of negativity and disapproval of their enrolment at the university. In addition, is the expressed feeling that during the course of their study, lecturers do not accord adult learners the opportunity to have any meaningful input to the programmes being offered to them. Coker (2003) makes an observation about women adult learners' expressed concern about being marginalized as adult learners, and the areas in which such marginalization is manifested include relationships with faculty and interactions with others.

It would however appear that in spite of such concerns, there is the lack of support systems for adult learners in terms of social and induction programmes to mitigate the challenges they encounter trying to settle in their new environment. Lack of skills among lecturers to handle adult learners emerges as one possible reason to provide such needed support. This study therefore makes four recommendations based on the findings. These are as follows:

1. The institutions of higher learning should enquire from adult learners their challenges outside their learning environment that might adversely have a negative bearing on the study.

2. The institutions of higher learning should have in place comprehensive induction programmes which are aimed at providing adult learners with information that would help them settle in their new academic environment.

3. Adult learners' programmes should from time to time be revisited with the aim to give learners the opportunity to make their own evaluation of their experience since entering the university with the aim to make some improvement.

4. There should be in place in-service programmes aimed at providing lecturers with skills required to teach adult learners.

\section{Acknowledgement}

We would like to thank the Office of Research and Development (ORD) of the University of Botswana for funding this study. 


\section{References}

Armour, K. M., \& Yelling, M. R. (2004). Continuing professional development for experienced physical education teachers: towards effective provision. Sport, Education and Society, 9(1), 95-114. http://dx.doi.org/10.1080/1357332042000175836

Akinsola, H. A. \& Popovich, J. M. (2002). The Quality of Life of Families of Female-Headed Households in Botswana: A Secondary Analysis of Case Studies. Health Care for Women International, 23, 761-772. http://dx.doi.org/10.1080/07399330290107502

Ausburn, L. J. (2004). Course Design Elements Most Valued by Adult Learners in Blended Online Education Environments: An American Perspective. Educational Media International, 41(4), 327-337. http://dx.doi.org/10.1080/0952398042000314820

Bogdan, R. C., \& Biklen, S. K. (1992). Qualitative research for education: An introduction to theory and methods. Boston: Allyn and Bacon.

Brannen, J. (2005). Mixing methods: The entry of qualitative and quantitative approaches into the research process [Electronic version]. International Journal of Social Research Methodology, 8(3), 75-184. http://dx.doi.org/10.1080/13645570500154642

Brownlee, J., Purdie, N., \& Boulto-Lewis, G. (2001). Changing epistemological beliefs in pre-service teacher education students. Teaching in Higher Education, 6(2), 247-268. http://dx.doi.org/10.1080/13562510120045221

Coker, A. D. (2003). African American Female Adult Learners: Motivation, Challenges, and Coping Strategies. Journal of Black Studies, 33(5), 654-674. http://dx.doi:10.1177/0021934703033005007

Creswell, J. W. (2007). Qualitative Inquiry Research Design: Choosing Among Five Approaches. London: Sage Publications

Creswell, J. W., Clark, V. L. P., Gutmann, M. L. \& Hanson, W. L. (2003). Advanced mixed methods research designs. In A. Tashakkori \& C. Teddlie. (Eds.). Handbook of mixed methods in social \& behavioural research (pp. 209-240). London: Sage Publication.

Crowther, J., Maclachlan, K. \& Tett, L. (2010). Adult literacy, learning identities and pedagogic practice. International Journal of Lifelong Education, 29(6), 651-664. http://dx.doi.org/10.1080/02601370.2010.524010

Fraser, C., Kennedy, A., Reid, L., \& Mckinney, S. (2007). Teachers' continuing professioal development: contested concepts, understanding and models. Journal of Inservice Education, 33(2), 153-169. http://dx.doi.org/10.1080/13674580701292913

Huang, H. M. (2002). Toward constructivism for adult learners in online learning environments. British Journal of Educational Technology, 33(1), 27-37. http://dx.doi:10.1111/1467-8535.00236

Illeris, K. (2003). Adult education as experienced by the learners. International Journal of Lifelong Education, 22(1), 13-23. http://dx.doi.org/10.1080/02601370304827 
Johnson, L. G., Schwarz, R. A., \& Bower, B. L. (2010). Managing Stress Among Adult Women Students in Community Colleges. Community College Journal of Research and Practice, 24, 289-300. http://dx.doi.org/10.1080/106689200264079

Kasworm, C. (2005). Adult Student Identity in an Intergenerational Community ollege Classroom. Adult Education Quarterly, 56(3). http://dx.doi:10.1177/0741713605280148

Kasworm, E. C. (2008). Emotional Challenges of Adult Learners in Higher Education. New Directions for Adult and Continuing Education, 120, 27-34. http://dx.doi:10.1002/ace.313

Kasworm, E. C. (2010). Adult Learners in a Research University: Negotiating Undergraduate Student Identity. Adult Education Quarterly, 60(2), 143-160. http://dx.doi:10.1177/0741713609336110

Knight, P. (2001). A systematic approach to professional development: learning as practice. Teaching and Teacher Education, 18, 229-241. http://dx.doi.org/10.1016/S0742-051X(01)00066-X

Kostanodivic, D. (2011). Education and Continuing Professional Development. Journal Plus Education, vii(2), 126-136.

Laot, F. F. (2010). Adult learners in France in the 1960s: a socio-historical approach to the relationship to knowledge. International Journal of Lifelong Education, 29(6), 665-677. http://dx.doi.org/10.1080/02601370.2010.524002

Lockenhoff, E.C., \& Carstensen, L. L. (2004). Socioeconomic Selectivity Theory, Aging, and Health: The Increasing Delicate Balance Between Regulating Emotions and Making Tough $\begin{array}{llll}\text { Choices. Journal of } & \text { Personality, } & \text { 1395-1424. }\end{array}$ http://dx.doi:10.1111/j.1467-6494.2004.00301.x

Lockyer, S. (2006). Heard the one about ...applying mixed methods in humour research [Electronic version]. International Journal of Social Research Methodology, 9(1), 41-59. http://dx.doi.org/10.1080/13645570500436155

Onwuegbuzie, A. J., \& Leech, N. L. (2005). On becoming a pragmatic researcher: The importance of combining quantitative and qualitative research methodologies [Electronic version]. International Journal of Social Research Methodology, 8(5), 375-387. http://dx.doi.org/10.1080/13645570500402447

Pansiri, O. N. (2007). Teacher Remuneration: A Critical Policy Review in Botswana. Pula Journal of African Studies, 21(1), 199-217.

Pansiri, O. N. (2011). Performativity in school management and leadership in Botswana. Educational Management Administration and Leadership, 39(6), 751-766. http://dx.doi:10.1177/1741143211416386

Pansiri, O. N., Mhozya, C. M., Moletsane, N. T., \& Bulawa, P. (2012). Socio-emotional Selectivity: A preliminary analysis of Perspectives of Adult Learners in the University of Botswana. International Education Studies, 5(4), 46-55. 
http://dx.doi.org/10.5539/ies.v5n4p46

Pascall, G. \& Cox, R. (1993). Women Returning to Higher Education. Buckingham, SRHE/Open University Press.

Patton, M. Q. (2002). Qualitative research and evaluation methods. (3rd Ed). London: Sage Publishing.

Republic of Botswana (1994). The Revised National Policy on Education. Gaborone: Government Printer.

Ritchie, J., Lewis, J., \& Elam, G. (2004). Designing and selecting samples. In J. Ritchie and J. Lewis. (Eds.). Qualitative research practice: A guide for social science students and researchers (pp. 77-107). London: SAGE Publications.

Schwandt, T. A. (2000). Three epistemological stances for qualitative enquiry: Interpretivism, hermeneutics and social constructivism. In N. K. Denzin \& Y. S. Lincoln. (Eds.). Handbook of Qualitative Research, $2^{\text {nd }}$ Ed. (pp. 189-213). London: Sage Publications.

Stark, S., \& Torrance, H. (2005). Case study. In B. Somekh \& C. Lewin. (Eds). Research methods in the social sciences. (pp. 33-40). London: Sage Publications.

Tashakkori, A., \& Teddlie, C. (1998). Mixed methodology: combining qualitative and quantitative approaches. London: Sage Publishing. 